\title{
AEROBIC AND ANAEROBIC THRESHOLD DETERMINED BY SPECIFIC TEST IN JUDO IS NOT CORRELATED WITH GENERAL TEST
}

\section{AEROBIC AND ANAEROBIC THRESHOLD IN JUDO}

Paulo Azevedo ${ }^{1,4^{*}}$, João Carlos Oliveira ${ }^{2}$, Alessandro Zagatto ${ }^{3}$, Paulo Eduardo Pereira ${ }^{4}$, Sergio Eduardo Andrade Perez ${ }^{5}$

${ }^{1}$ Human Movement Science Department, Federal University of São Paulo, Santos, São Paulo, Brazil.

${ }^{2}$ Physical Education Department, Hermínio Ometto University, Araras, São Paulo, Brazil; jcrls.de.oliveira@gmail.com (J.C.O)

${ }^{3}$ Physical Education Department, UNESP, Bauru, São Paulo, Brazil; azagatto@fc.unesp.br (A.Z)

${ }^{4}$ Group of Studies and Research in Exercise Physiology, Federal University of São Paulo, Santos, São Paulo, Brazil; pereira.pauloeduardo@hotmail.com (P.E.P)

${ }^{5}$ Physiological Science Department, Federal University of São Carlos, São Carlos, São Paulo, Brazil; seaperez@ufscar.br (S.E.A.P)

* Correspondence: gepefex.unifesp@gmail.com; Tel.: +55 13 3878-3700

\begin{abstract}
TH}_{\mathrm{aer}}\right)$ and anaerobic threshold $\left(\mathrm{TH}_{\text {anaer }}\right)$ measured during a new single judo specific incremental test and Treadmill Test for aerobic demand evaluation. Eight well-trained male competitive judo players (24.3 \pm 7.9 years; height of $169.3 \pm 6.7 \mathrm{~cm}$; fat mass of $12.7 \pm 3.9 \%$ ) performed a maximal incremental specific test for judo mimicking the UchiKomi drills and on treadmill in different days. There was difference between specific and general $\mathrm{TH}_{\mathrm{aer}}(P=0.0006)$ as well as weak correlation for $\mathrm{TH}_{\mathrm{aer}}\left(\mathrm{r}=0.32 ; \mathrm{R}^{2}=0.1 ; P=0.2\right)$ and $\mathrm{TH}_{\text {anaer }}$ ( $\left.\mathrm{rs}=-0.31 ; \mathrm{R}^{2}=0.1 ; P=0.12\right)$. When correlation was applied with normalized data (percentage of peak load) we observed moderate correlation for $\mathrm{TH}_{\mathrm{aer}}\left(\mathrm{r}=0.76 ; \mathrm{R}^{2}=0.58 ; P=0.027\right)$, but the same was not observed for $\mathrm{TH}_{\text {anaer }}$ We conclude that there is a need of $\mathrm{TH}_{\mathrm{aer}}$ and $\mathrm{TH}_{\text {anaer }}$ evaluation through a specific test for Judo.
\end{abstract}

Keywords: anaerobic threshold, martial art, sport 


\section{Introduction}

Our group has studied modes to evaluate the aerobic capacity in fighter athletes' through specific tests [1-3]. Recently we validated an incremental test to determine the ventilatory threshold in judo athletes [1]. As Judo is predominantly aerobic, intermittent and has several fights during a day [4], aerobic capacity assessment is important to evaluate the adaptation facing systematic training process and intensity training prescription. It has been suggested that the better aerobic capacity determination is dependent of specificity and validity of utilized test [5-7]. Here we analyzed whether the specific test is correlated with general test. It is expected a weak correlation, pointing out a need of specific evaluation.

The aerobic and anaerobic threshold determination has been held through general protocol in judo athletes [8-10]. However general tests do not mimic the specificity of judo, like Uchikomi drills and hold on kimono sleeves (judogui) [10]. Therefore, we believe that specific evaluation is required and general test cannot be used to predict ideal intensity to training and is not sensible to evaluate the athletes' adaptation facing a training programmer.

Then, the aims of this study were: 1 - to correlate aerobic and anaerobic threshold determined by specific test (Uchikomi) with that in treadmill (general) test; 2- to compare the relative intensities of thresholds between specific and general tests. Our hypotheses are that there is a weak correlation between tests, and there are not any differences between thresholds relative to peak load.

\section{Materials and Methods Subjects}

\subsection{Participants}

Eight well-trained male judo athletes (mean age of $24.2 \pm 6.4$ years old; height of $168.2 \pm 7.0$ $\mathrm{cm}$; body mass of $65.4 \pm 13.2-\mathrm{kg}$ ) participated voluntarily in this study. Four judo athletes competed in national-level tournaments, whereas four other plays in state competitions. The mean time spent on training was $10.5 \pm 0.4$ hours a week. All participants were textually and verbally informed about the possible intrinsic risks and benefits of the tests, signing a free informed consent. The study was approved by the research ethics committee of the Federal University of São Carlos, Brazil (Human Research Ethics Committee protocol number 257/2006).

\subsection{Experimental design}

All the subjects performed a specific incremental test mimicking the Uchikomi using a cable crossover machine [1] and a running treadmill test. Both tests were performed until exhaustion. The tests were conducted at the same period of the day with a variation of 2 hours and the interval between tests was one week.

Warm-up exercises consisting of specific judo movements were performed for 5 minutes prior to each test. To minimize the learning effect, the judo athletes attended 5-minute UchiKomi sessions using a cable crossover machine for 4 non consecutive days [11]. The pace of Uchikomi was controlled through loud signs emitted by a metrometer.

\subsection{Experimental Procedures}

To determine the aerobic and anaerobic threshold, the subjects were submitted to an incremental test (treadmill (general) test) on a treadmill (Movement LX-150) at an inclination of $1 \%$ and initial 
velocity of $6 \mathrm{~km} \cdot \mathrm{h}^{-1}$, followed by increments of $1 \mathrm{~km} \cdot \mathrm{h}^{-1}$ with intervals of 3 minutes between stages $[12,13]$.

Measurements of $\mathrm{VO}_{2}, \mathrm{VCO}_{2}$ and ventilation were carried out throughout each test using a telemetry system $\left(\mathrm{K}_{4} \mathrm{~b}^{2}\right.$, Cosmed, Rome, Italy). Expired gases were measured breath-by-breath and the results were averaged every 15 seconds. Before each test, the system was calibrated using ambient air and a gas of known $\mathrm{O}_{2}$ and $\mathrm{CO}_{2}$ concentration according to the manufacturer's instructions $\left(\mathrm{K} 4 \mathrm{~b}^{2}\right.$ instruction manual) and subjects remain standing during 5 minutes for data acquisition and normalization. The turbine flow-meter of the $\mathrm{K} 4 \mathrm{~b}^{2}$ was calibrated using a 3-L syringe.

The aerobic threshold $\left(\mathrm{TH}_{\mathrm{aer}}\right)$ was determined by three ventilatory parameters: 1) first loss in ventilatory linearity; 2) increase in ventilatory equivalent of $\left.\mathrm{O}_{2}\left(\mathrm{VE} / \mathrm{VO}_{2}\right) ; 3\right)$ increase in the fraction of expired $\mathrm{O}_{2}\left(\% \mathrm{FeCO}_{2}\right)$ [14]. The anaerobic threshold $\left(\mathrm{TH}_{\text {anaer }}\right)$ was determined by three ventilatory parameters: 1) second loss in ventilatory linearity; 2) increase in ventilatory equivalent of $\mathrm{CO}_{2}$ $\left.\left(\mathrm{VE} / \mathrm{VCO}_{2}\right) ; 3\right)$ decrease in the fraction of expired $\mathrm{CO}_{2}\left(\% \mathrm{FeCO}_{2}\right)$ [14]. Two experienced scientists evaluated each graph, and in case of discrepancies, the mean of the identified points was used.

Specific Incremental Judo Test:

The test was developed so that uchikomi would be applied in association with ippon-seoi-nague technique using a cable crossover machine, with kimono sleeves adaptation onto the crossover machine. The validity and reliability of UchiKomi use for anaerobic threshold determination has been demonstrated previously [15]. Warm-up exercises consisted of 5-minutes with specific judo movements. To minimize the learning effect, the judo athletes attended 5-minute UchiKomi sessions using a cable crossover machine for 4 non consecutive days [11]. The pace of Uchikomi was controlled through loud signs emitted by a metrometer. Initial load was $1.9-\mathrm{kg}$, increasing $1.2-\mathrm{kg}$ every 3 minutes [16]. The UchiKomi movements had a frequency of one UchiKomi every 3 seconds [10]. The test was finished when the subject stopped the movement voluntarily due to exhaustion, when the pre-determined frequency was not kept during 3 consecutive Uchikomi, or when Uchikomi was performed out of the technical pattern.

The aerobic threshold $\left(\mathrm{TH}_{\mathrm{aer}}\right)$ was determined by three ventilatory parameters: 1) first loss in ventilatory linearity; 2) increase in ventilatory equivalent of $\left.\mathrm{O}_{2}\left(\mathrm{VE} / \mathrm{VO}_{2}\right) ; 3\right)$ increase in the fraction of expired $\mathrm{O}_{2}$ $\left(\% \mathrm{FeCO}_{2}\right)$ [14]. The anaerobic threshold $\left(\mathrm{TH}_{\text {anaer }}\right)$ was determined by three ventilatory parameters: 1$)$ second loss in ventilatory linearity; 2) increase in ventilatory equivalent of $\left.\mathrm{CO}_{2}\left(\mathrm{VE} / \mathrm{VCO}_{2}\right) ; 3\right)$ decrease in the fraction of expired $\mathrm{CO}_{2}\left(\% \mathrm{FeCO}_{2}\right)$ [14]. Two experienced scientists evaluated each graph, and in case of discrepancies, the mean of the identified points was used.

\subsection{Statistical Analysis}

Data is presented as mean $\pm \mathrm{SD}$. The Shapiro-Wilk test was applied to assess the normality of data. The differences between the relative intensity of specific and general thresholds were analyzed with a paired $t$-test, and Pearson's correlation coefficient. When data was non-parametric the comparison was made by Wilcoxon test and correlation by Spearman. The significant level was set at $P \leq 0.05$. 


\section{Results}

The overall results (load and velocity) of the parameters studied are shown in Table 1. Aerobic threshold was $7.1 \pm 1.7 \mathrm{~kg}$ and $7.7 \pm 1.2 \mathrm{~km} \cdot \mathrm{h}^{-1}$ for specific and general tests, respectively; Anaerobic threshold was $10.3 \pm 1.9 \mathrm{~kg}$ and $10 \pm 1.2 \mathrm{~km} . \mathrm{h}^{-1}$ for specific and general testes, respectively.

Table 1. Relative intensity of aerobic threshold $\left(\mathrm{TH}_{\mathrm{aer}}\right)$ and $\mathrm{TH}_{\text {anaer }}$ for overall subjects $(\mathrm{n}=8)$ in specific and general tests.

\begin{tabular}{|c|c|c|c|c|}
\hline Subject & SpecificTH $_{\text {aer }}(\mathrm{kg})$ & $\begin{array}{c}\text { SpecificTH } \text { anaer }_{\text {en }} \\
(\mathrm{kg})\end{array}$ & $\begin{array}{c}\text { GeneralTH } \\
\left(\mathrm{km} \cdot \mathrm{h}^{-1}\right)\end{array}$ & $\begin{array}{c}\text { GeneralTH } \\
\text { anaer } \\
\left(\mathrm{km} \cdot \mathrm{h}^{-1}\right)\end{array}$ \\
\hline 1 & 7.6 & 11.3 & 8 & 9 \\
\hline 2 & 4.3 & 6.8 & 7 & 10 \\
\hline 3 & 6.8 & 10 & 7 & 8 \\
\hline 4 & 9.1 & 11.3 & 10 & 12 \\
\hline 5 & 5.3 & 9.1 & 7 & 10 \\
\hline 6 & 6.8 & 11.3 & 6 & 9 \\
\hline 7 & 6.8 & 9.1 & 8 & 11 \\
\hline 8 & 10 & 13.6 & 9 & 11 \\
\hline Mean & 7.1 & 10.3 & 7.7 & 10 \\
\hline SD & 1.7 & 1.9 & 1.2 & 1.2 \\
\hline
\end{tabular}

Specific $\mathrm{TH}_{\text {aer: }}$ : specific aerobic threshold; Specific $\mathrm{TH}_{\text {anaer }}$ : specific anaerobic threshold; GeneralTH $\mathrm{aer}_{\text {: }}$

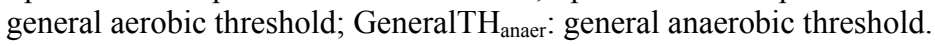

The relative intensity load at specific aerobic threshold was significantly different compared to general test $(P=0.0006)$ (Table 2$)$ with $56.3 \pm 5.7 \%$ and $65.8 \pm 7.4 \%$ of maximum intensity for general and specific tests, respectively. No difference was observed for anaerobic threshold $(P=0.2)$ (Table 2) with $82.6 \pm 2.8 \%$ and $84.8 \pm 4.3 \%$ of maximum intensity for general and specific tests, respectively.

Table 2. Relative intensity in percentage of maximum intensity for general and specific tests.

\begin{tabular}{c|cccc}
\hline Subject & $\begin{array}{c}\text { GeneralTH } \\
\max )\end{array}$ & $\begin{array}{c}\text { General }\left(\% H_{\text {anaer }}\right. \\
(\% \max )\end{array}$ & $\begin{array}{c}\text { Specific TH } \\
(\% \max )\end{array}$ & $\begin{array}{c}\text { SpecificTH }_{\text {anaer }} \\
(\% \max )\end{array}$ \\
\hline 1 & 55.7 & 82.8 & 72.7 & 81.8 \\
2 & 56.6 & 89.5 & 58.3 & 83.3 \\
3 & 55.3 & 81.3 & 70 & 80 \\
4 & 66.7 & 82.8 & 76.9 & 92.3 \\
5 & 46.9 & 80.5 & 58.3 & 83.3 \\
6 & 50 & 83.1 & 54.5 & 81.8 \\
7 & 60.2 & 80.5 & 66.7 & 91.7 \\
8 & 58.8 & 80.3 & 69.2 & 84.6 \\
Mean & 56.3 & 82.6 & 65.8 & 84.8 \\
SD & 5.7 & 2.8 & 7.4 & 4.3 \\
\hline
\end{tabular}

GeneralTH$_{\text {aer }}$ : general aerobic threshold; GeneralTH$H_{\text {anaer: }}$ general anaerobic threshold; SpecificTH ${ }_{\text {aer: }}$ : specific aerobic threshold; Specific $\mathrm{TH}_{\text {anaer}}$ : specific anaerobic threshold

There were a weak correlation between specific and general aerobic threshold $\left(r=0.32 ; R^{2}=0.1\right.$; $P=0.2)$, as well as for anaerobic threshold $\left(\mathrm{r}=-0.31 ; \mathrm{R}^{2}=0.1 ; P=0.12\right)$. When correlation was done by relative intensity we observed a moderate correlation for aerobic threshold $\left(\mathrm{r}=0.76 ; \mathrm{R}^{2}=0.58 ; P=0.027\right)$ and weak correlation for anaerobic threshold ( $\mathrm{rs}=-0.29 ; P=0.48)$. 


\section{Discussion}

The main finding was that there was a weak correlation between tests showing us a need to assess the aerobic capacity in judo athletes by mean of a specific test. The relative $\mathrm{TH}_{\text {aer }}$ and $\mathrm{TH}_{\text {anaer }}$ were similar to values reported in literature for general tests. But, when compared, $\mathrm{TH}_{\mathrm{aer}}$ was different between tests.

The aerobic and anaerobic threshold determination through general test (treadmill and cycleergometer) was not able to discriminate the judo athletes level $[17,18]$. Therefore, is compulsory the use of specific test to assess the physical fitness of athletes [7,19]. However, there are few specific tests for judo $[7,10,20]$. One of them demonstrated the similarity for metabolic and heart rate response between running and Uchikomi on lactate minimum determination [10]. But, it was not validated yet. A weak correlation has been observed when thresholds are assessed in specific and general tests [21,22]. The difference on motor pattern between specific and general tests could explain the weak correlation observed. Therefore, the treadmill and cycle-ergometer tests are not sensitive to specific adaptation arising for judo training.

The ventilatory response and gas exchange during specific incremental test for judo were not known. However the same pattern found in general test was expected, according to another study [10]. It was able to assess the aerobic and anaerobic threshold for all subjects. This innovative methodology will contribute to specific training and evaluation for judo [23,24] and performance improvement as well [8].

The relative aerobic and anaerobic thresholds were similar to those reported for general tests [2527]. The relative intensity of specific aerobic threshold was higher than aerobic threshold determined on treadmill $(65.8 \pm 7.4$ vs $56.3 \pm 5.7 \% ; P=0.0006)$. It shows that the adaptations are specific, so the athlete evaluation must be done in a specific way as well. The same result was not observed for anaerobic threshold. The possible explanation is that this data was non-parametric, then the subjects' number was fewer than expected and the statistic Power was unable to show us difference between specific and widespread tests.

It is suggested that more offensive judo player style has higher anaerobic capacity [23] than defensive judo player which has better aerobic capacity. Then, more defensive judo player could train in intensity between aerobic and anaerobic threshold because they have several fights during the day each one with longer duration. On the other hand offensive athletes could train in intensity above anaerobic threshold because they need faster anaerobic metabolism to ATP resynthesis during the combat.

\section{Conclusion}

We concluded that there are weak relationships between specific and general tests for aerobic and anaerobic thresholds confirming our first hypothesis. Additionally, our second hypothesis was partially observed because the relative aerobic threshold intensity was different between tests. The ventilatory response pattern and gas exchange during a specific incremental test for judo was similar to those reported in general tests showing us the concurrent validity of a specific test for judo. Therefore, we must assess the thresholds through a specific test in judo instead of through general tests.

Acknowledgments: The authors would like to thank the participants in this investigation who made this work possible and the English revision made by Carmen Andrea Perez. 
Author Contributions: Paulo Azevedo wrote and made the statistical approach; João Carlos Oliveira, Alessandro Zagatto and Sergio Eduardo Andrade Perez conceived, designed the experiments and collected the data; Paulo E. Pereira Esteves reviewed and made the intellectual contribution.

Conflicts of Interest: The authors declare no conflict of interest.

Ethical approval: All procedures performed in studies involving human participants were in accordance with the ethical standards of the Human Ethics Committee of the Federal University of São Carlos and with the Helsinki declaration and its later amendments or comparable ethical standards.

Informed consent: Informed consent was obtained from all individual participants included in the study.

\section{References}

1. Azevedo, P.; Pithon-Curi, T.; Zagatto, A.M.; Oliveira, J.; Perez, S. Maximal lactate steady state in judo. Muscles Ligaments Tendons J 2014, 4, 132-136.

2. Burger-Mendonca, M.; de Oliveira, J.C.; Cardoso, J.R.; Bielavsky, M.; Azevedo, P. Changes in blood lactate concentrations during taekwondo combat simulation. J Exerc Rehabil 2015, 11, 255-258.

3. da Mota, G.R.; Magalhães, C.G.; Azevedo, P.; Ide, B.N.; Lopes, C.R.; Castardeli, E.; Neto Barbosa, O.; Marocolo Junior, M.; Baldissera, V. Lactate threshold in taekwondo through specifics tests. JEPonline 2011, 14, 60-66.

4. Franchini, E.; Nunes, A.V.; Moraes, J.M.; Del Vecchio, F.B. Physical fitness and anthropometrical profile of the brazilian male judo team. J Physiol Anthrop 2007, 26, 59-67.

5. Almansba, R.; Franchini, E.; Sterkowiczc, S. An uchi-komi with load, a physiological approach of a new special judo test proposal. Science \& Sports 2007, 22, 216-223.

6. Azevedo, P.H.S.M.; Drigo, A.J.; Carvalho, M.C.G.A.; Oliveira, J.C.; Nunes, J.E.D.; Baldissera, V.; Perez, S.E.A. Determination of judo endurance performance using the uchi - komi technique and an adapted lactate minimum test. J Sports Sci \& Med 2007, 6, 10-14.

7. Blais, L.; Trilles, F.; Lacouture, P. Validation of a specific machine to the strength training of judokas. J Strength Cond Res 2007, 21, 409-412.

8. Azevedo, P.H.S.M.; Drigo, A.J.; Oliveira, P.R.; Carvalho, M.C.G.A.; Sabino Jr, M. A systematization of the training period of the judo athlete mario sabino: A case study on the year 2003. Rev Bras Cienc Esporte 2004, 26, 73-86.

9. Drigo, A.J.; Amorim, A.R.; Kokubun, E. Avaliação do condicionamento físico em judocas através do lactato sanguíneo. Rev Bras Cienc Mov 1994, Simpósio Internacional de Ciências do Esporte. São Paulo, Brazil: CELAFISCS, Brazil, 156.

10. Azevedo, P.H.; Drigo, A.J.; Carvalho, M.C.; Oliveira, J.C.; Nunes, J.E.; Baldissera, V.; Perez, S.E. Determination of judo endurance performance using the uchi - komi technique and an adapted lactate minimum test. J Sports Sci Med 2007, 6, 10-14.

11. Papoti, M.; Vitório, R.; Araújo, G.G.; Silva, A.S.R.; Santhiago, V.; Martins, L.E.B.; Cunha, S.A.; Gobatto, C.A. Determination of force corresponding to maximal lactate steady state in tethered swimming. Int J Exerc Sci 2009, 2, 269-279.

12. Jones, A.M.; Doust, J.H. A $1 \%$ treadmill grade most accurately reflects the energetic cost of outdoor running. J Sports Sci 1996, 14, 321-327.

13. Azevedo, P.H.S.M.; Oliveira, J.C.; Simões, H.G.; Baldissera, V.; Perez, S.E.A. Oxygen uptake kinetics and threshold time at the $\mathrm{vvo}_{2}$ max: Comparison between men and women. Rev Bras Med Esporte 2010, 16, 278-281.

14. Bhambhani, Y.; Singh, M. Ventilatory thresholds during a graded exercise test. Respiration 1985, 47, 120-128.

15. Santos, L.; Gonzalez, V.; Iscar, M.; Brime, J.I.; Fernandez-Rio, J.; Egocheaga, J.; Rodriguez, B.; Montoliu, M.A. A new individual and specific test to determine the aerobic-anaerobic transition zone (santos test) in competitive judokas. J Strength Cond Res 2010, 24, 2419-2428.

16. Bentley, D.J.; Newell, J.; Bishop, D. Incremental exercise test design and analysis: Implications for performance diagnostics in endurance athletes. Sports Med 2007, 37, 575-586.

17. Taylor, A.W.; Brassard, L. A physiological profile of the canadian judo team. J Sports Med 1981, 21, 160-164.

18. Franchini, E.; Takito, M.Y.; Lima, J.R.P.; Haddad, S.; Kiss, M.A.P.D.M.; Regazzini, M.; Böhme, M.T.S. Características fisiológicas em testes laboratoriais e resposta da concentração de lactato sanguíneo em três lutas em judocas das classes juvenil-a, junior e sênior. Rev Paul Educ Física 1998, 12, 5-16. 
19. Girard, O.; Chevalier, R.; Leveque, F.; Micallef, J.P.; Millet, G.P. Specific incremental field test for aerobic fitness in tennis. Br J Sports Med 2006, 40, 791-796.

20. Sterkowicz, S.; Zuchowicz, A.; Kubica, R. Levels of anaerobic and aerobic capacity indices and results for the special judo fitness test in judo competitors. Journal of Human Kinetics 1999, 2 , 115-135.

21. Zagatto, A.M.; Papoti, M.; Gobatto, C.A. Comparison between specific and conventional ergometers in the aerobic capacity determination in table tennis players. Rev Bras Med Esporte 2009, 15, 204 - 208.

22. Girard, O.; Sciberras, P.; Habrard, M.; Hot, P.; Chevalier, R.; Millet, G.P. Specific incremental test in elite squash players. Br J Sports Med 2005, 39, 921-926.

23. Thomas, S.G.; Cox, M.H.; LeGal, Y.M.; Verde, T.J.; Smith, H.K. Physiological profiles of the canadian national judo team. Can J Sport Sci 1989, 14, 142-147.

24. Tumilty, D.; Hahn, A.; Telford, R.D. A physiological profile of well-trained male judo players, with proposals for training. Excel 1986, 2, 12-14.

25. Dekerle, J.; Baron, B.; Dupont, L.; Vanvelcenaher, J.; Pelayo, P. Maximal lactate steady state, respiratory compensation threshold and critical power. Eur J Appl Physiol 2003, 89, 281-288.

26. Wasserman, K.; Whipp, B.J.; Koyl, S.N.; Beaver, W.L. Anaerobic threshold and respiratory gas exchange during exercise. J Appl Physiol 1973, 35, 236-243.

27. Green, J.M.; Crews, T.R.; Bosak, A.M.; Peveler, W.W. A comparison of respiratory compensation thresholds of anaerobic competitors, aerobic competitors and untrained subjects. Eur J Appl Physiol 2003, 90, 608-613. 